\title{
Multiple Lower Extremity Mononeuropathies by Segmental Schwannomatosis: A Case Report
}

\author{
Na Yeon Kwon, MD, Hyun-Mi Oh, MD, Young Jin Ko, MD, PhD
}

\author{
Department of Rehabilitation Medicine, College of Medicine, The Catholic University of Korea, Seoul, Korea
}

\begin{abstract}
Schwannoma is an encapsulated nerve sheath tumor that is distinct from neurofibromatosis. It is defined as the occurrence of multiple schwannomas without any bilateral vestibular schwannomas. A 46-year-old man with multiple schwannomas involving peripheral nerves of the ipsilateral lower extremity presented with neurologic symptoms. Electrodiagnostic studies revealed multiple mononeuropathies involving the left sciatic, common peroneal, tibial, femoral and superior gluteal nerves. Histologic findings confirmed the diagnosis of schwannoma. We reported this rare case of segmental schwannomatosis that presented with neurologic symptoms including motor weakness, which was confirmed as multiple mononeuropathies by electrodiagnostic studies.
\end{abstract}

Keywords Schwannomatosis, Mononeuropathies, Electromyography

\section{INTRODUCTION}

Schwannoma is mostly a solitary lesion as reported by Park et al. [1]. However, it can occur as multiple lesions in patients with neurofibromatosis or schwannomatosis [2]. These are characterized by the multiple schwannomas in the absence of bilateral vestibular schwannomas [3]. Pain is reported in several cases with schwannomatosis along the peripheral nerves $[4,5]$. However, motor weakness by multiple mononeuropathies has rarely been reported. We presented this rare case of segmental schwannomatosis with electrodiagnostic confirmation of multiple mono-

Received August 13, 2014; Accepted November 6, 2014

Corresponding author: Young Jin Ko

Department of Rehabilitation Medicine, College of Medicine, The Catholic University of Korea, 222 Banpo-daero, Seocho-gu, Seoul 06591, Korea

Tel: +82-2-2258-2822, Fax: +82-2-2258-2825, E-mail: yjko@catholic.ac.kr

(ㄷ) This is an open-access article distributed under the terms of the Creative Commons Attribution Non-Commercial License (http://creativecommons. org/licenses/by-nc/4.0) which permits unrestricted noncommercial use, distribution, and reproduction in any medium, provided the original work is properly cited.

Copyright $\odot 2015$ by Korean Academy of Rehabilitation Medicine neuropathies involving the left lower extremities.

\section{CASE REPORT}

A 46-year-old man presented with a 5-year history of tingling sensation in his left foot and weakness in his left great toe extension. He had visited other clinics for further evaluation, and a follow-up lower extremity magnetic resonance imaging (MRI) revealed multiple nodules along the course of sciatic, tibial and peroneal nerves (Fig. 1). He was referred to the orthopedic department in our hospital. Under the clinical impression of schwannomatosis, excisions were done at multiple distinct locations including superior and inferior parts of the posterior tibia, middle portion of posterior thigh, popliteal fossa, distal leg above medial ankle joint, distal and proximal portion of plantar aspect and around the common peroneal nerve. The lesions were grossly oval-shaped, multilobulated masses of $3 \mathrm{~cm}$ in the greatest dimension, and histologic findings confirmed schwannoma.

After 2 years, the patient was referred to our rehabilita- 
tion clinic with worsening of weakness and palpating nodules at the calf and medial portion of posterior thigh. Lower extremity MRI revealed well-defined masses along the neurovascular bundles. A T2-weighted image showed multiple hyperintense tumors along the course of tibial
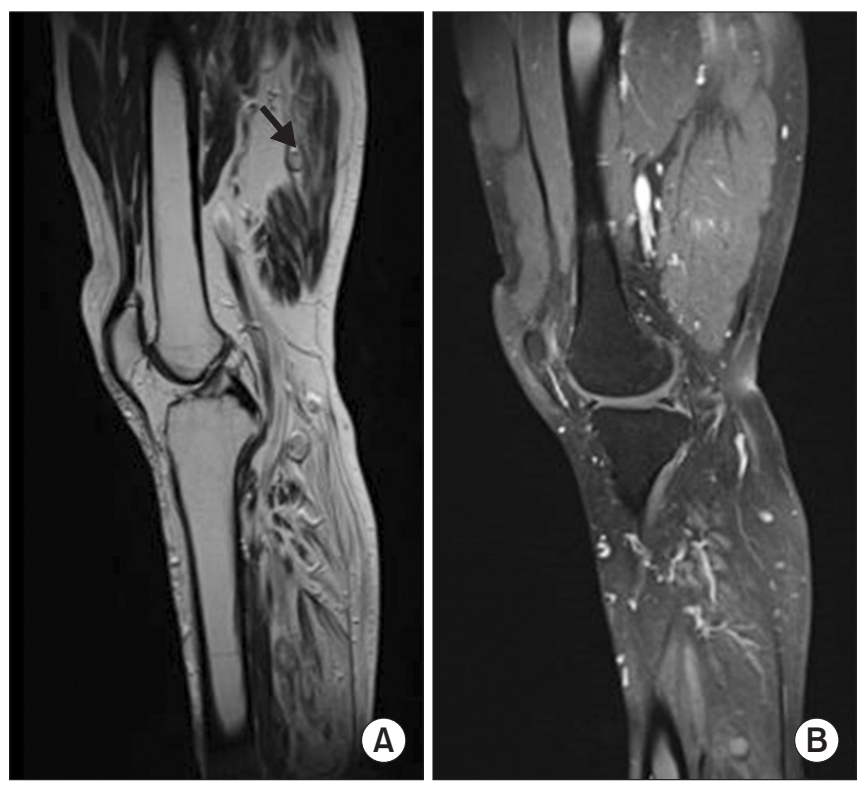

Fig. 1. (A) Initial sagittal T1-weighted image shows tumor inside medial hamstring muscle (arrow). (B) T2-weighted image demonstrates hyperintense lesions along the course of the sciatic nerve. and peroneal nerves with heterogeneous enhancement (Figs. 2, 3).

Medical Research Council scale for muscular weakness showed the following grades: left lower extremities with hip flexor $5 / 4$ (right/left), hip abductor $5 / 4$, hip extensor $5 / 4$, knee flexor $5 / 4$, knee extensor $5 / 4$, ankle dorsiflexor $5 / 3$, hallucis extensor $5 / 2$, and ankle plantar flexor $5 / 3$. The patient complained of tingling sensation below the left malleolus and left calf hyperalgesia. Deep tendon reflexes at left lower extremity were decreased.

Electrodiagnostic motor nerve conduction studies showed prolonged distal latencies, reduced compound muscle action potential amplitudes in the left tibial nerve and the left femoral nerve. The tibial nerve conduction velocities were decreased. In sensory nerve conduction studies, sensory nerve action potentials (SNAP) of the left sural nerve were not evoked. The SNAP amplitudes were reduced in the left superficial peroneal and saphenous nerves. H-wave study showed no response in the left tibial nerve. Needle electromyography revealed abnormal spontaneous activities in the left gluteus medius, biceps femoris (long head), peroneus longus, tibialis posterior, tibialis anterior and gastrocnemius muscles with substantially reduced interference patterns. Peroneal innervated muscles including left biceps femoris (short head) and peroneus longus showed large amplitudes and prolonged durations of motor unit action potentials (Tables 1, 2).
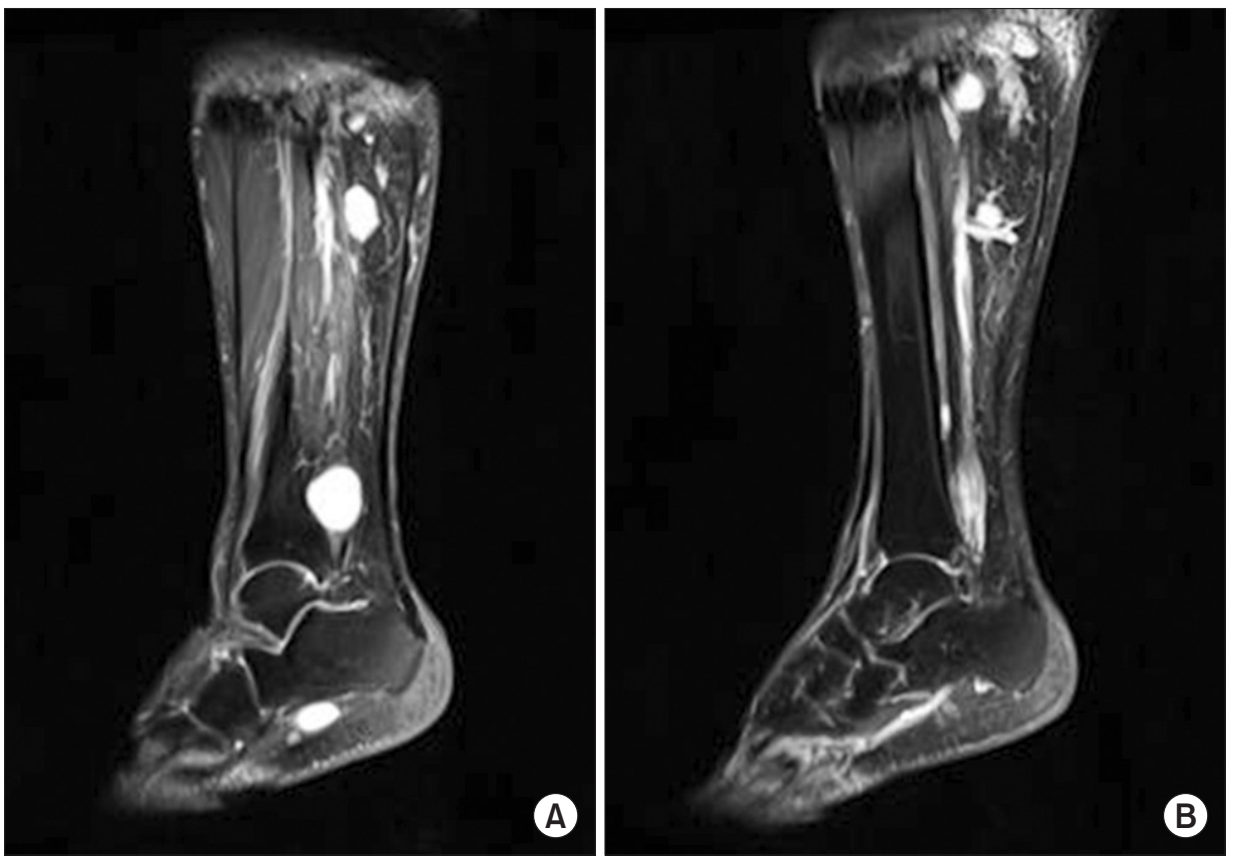

Fig. 2. (A) Sagittal T2-weighted image shows multiple hyperintense tumors along the course of the tibial nerve. (B) Proximal lesion has a similar appearance with a bright signal. 

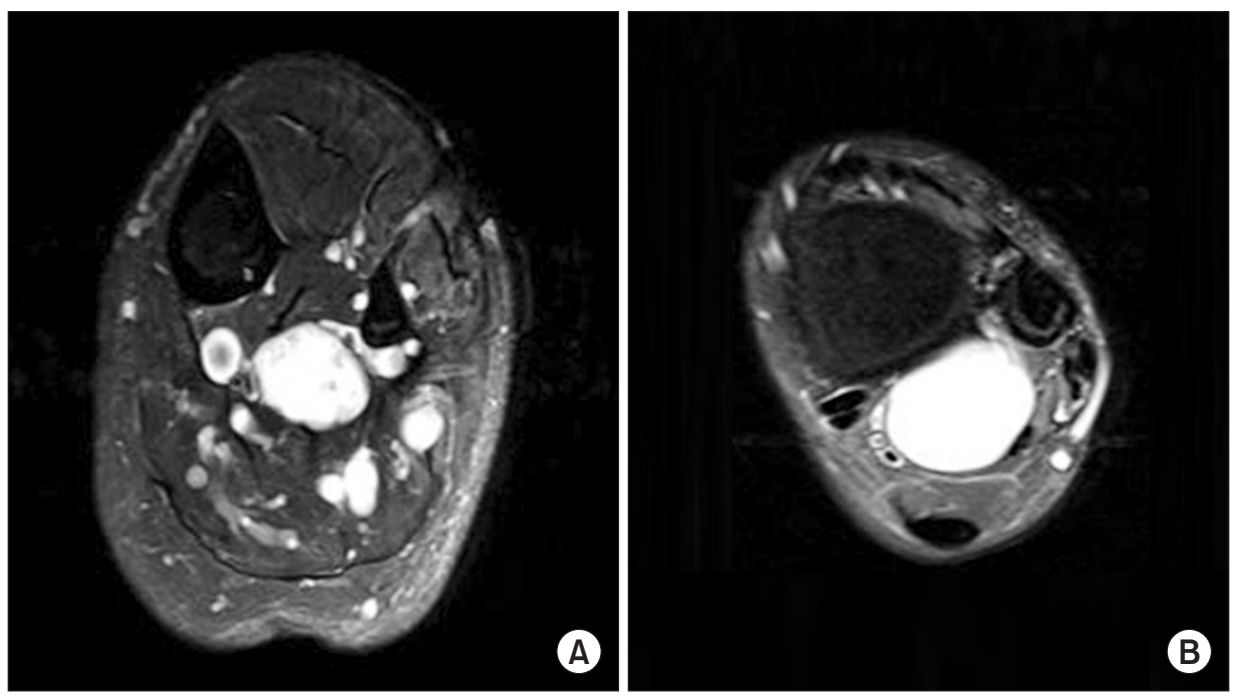

Fig. 3. (A) Axial T2-weighted image demonstrates the well-circumscribed lesions along the course of the tibial nerve. (B) Distal lesions are well-circumscribed and extend into the soleus muscle.

Table 1. Nerve conduction findings

\begin{tabular}{|c|c|c|c|c|c|c|c|}
\hline \multirow[b]{2}{*}{ Nerve } & \multirow[b]{2}{*}{ Stimulation } & \multicolumn{3}{|c|}{ Right } & \multicolumn{3}{|c|}{ Left } \\
\hline & & $\begin{array}{c}\text { Latency } \\
\text { (ms) }\end{array}$ & Amplitude $^{\text {a) }}$ & $\begin{array}{c}\mathrm{CV} \\
(\mathrm{m} / \mathrm{s})\end{array}$ & $\begin{array}{c}\text { Latency } \\
(\mathrm{ms})\end{array}$ & Amplitude $^{\text {a) }}$ & $\begin{array}{c}\mathbf{C V} \\
(\mathbf{m} / \mathbf{s})\end{array}$ \\
\hline \multicolumn{8}{|l|}{ Motor } \\
\hline Femoral & Inguinal area & 4.75 & 8.8 & - & 4.50 & 0.1 & - \\
\hline \multirow[t]{3}{*}{ Peroneal EDB } & Ankle & 3.70 & 5.8 & - & NR & NR & - \\
\hline & Fibular head & 11.45 & 4.7 & 42.6 & NR & NR & - \\
\hline & Knee & 13.20 & 4.6 & 51.4 & NR & NR & - \\
\hline \multirow[t]{2}{*}{ Peroneal TA } & Fibular head & 2.75 & 4.2 & - & 2.80 & 4.1 & - \\
\hline & Knee & 4.50 & 3.3 & 51.4 & 4.70 & 3.2 & 47.4 \\
\hline \multirow[t]{2}{*}{ Tibial } & Ankle & 4.70 & 16.8 & - & 7.85 & 0.3 & - \\
\hline & Popliteal fossa & 13.95 & 12.2 & 41.1 & 24.10 & 0.1 & 23.4 \\
\hline \multicolumn{8}{|l|}{ Sensory } \\
\hline Sural & Calf & 3.55 & 12.5 & - & $\mathrm{NE}$ & $\mathrm{NE}$ & - \\
\hline Superficial peroneal & Lateral leg & 3.25 & 9.3 & - & 3.45 & 3.2 & - \\
\hline Saphenous & Medial leg & 2.55 & 6.8 & - & 2.50 & 3.1 & - \\
\hline
\end{tabular}

$\mathrm{CV}$, conduction velocity; EDB, extensor digitorum brevis; TA, tibialis anterior; NE, not evoked; NR, no response.

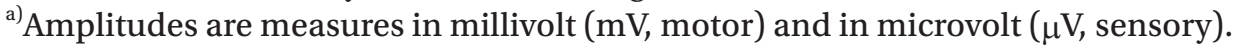

These results indicated that neurologic symptom was associated with multiple mononeuropathies involving left sciatic, common peroneal, tibial, femoral and superior gluteal nerves. The patient refused our recommendation of lumbosacral plexus MRI for possible plexopathy. He received conservative therapies that required continuous follow-up evaluations for any signs of recurrence.

\section{DISCUSSION}

Schwannomas are benign nerve sheath tumors that can arise along the course of nerves or spinal roots [2]. About $30 \%$ of schwannomatosis affect a single limb or one half of the body, as in our case $[4,6]$. Schwannomatosis limited to a single limb is defined as segmental schwannomatosis [3]. Patients complain of neurologic changes although these symptoms are uncommon unless the size of tumor becomes large [7]. Chronic pain, either local or 
Na Yeon Kwon, et al.

Table 2. Findings of needle electromyography in left lower extremity

\begin{tabular}{llccc}
\hline \multicolumn{1}{c}{ Muscle } & IA & ASA & MUAP & Interferential pattern \\
\hline Both paraspinalis (L3-S1) & Normal & None & & \\
\hline Gluteus maximus & Normal & None & Normal & Full \\
\hline Gluteus medius & Normal & ++ & Normal & Reduced \\
Adductor magnus & Normal & None & Normal & Reduced \\
\hline Iliopsoas & Normal & None & Normal & Reduced \\
Biceps femoris (short) & Normal & None & Large amplitude $(6 \mathrm{mV})$ & Discrete \\
\hline Biceps femoris (long) & Normal & ++ & Normal & Discrete \\
\hline Tibialis anterior & Normal & + & Normal & Reduced \\
\hline Tibialis posterior & Normal & + & Normal & Reduced \\
\hline Gastrocnemius (medial) & Normal & + & Normal & Reduced \\
\hline Peroneus longus & Normal & ++ & Large amplitude $(6 \mathrm{mV})$ & Discrete \\
\hline
\end{tabular}

IA, insertional activity; ASA, abnormal spontaneous activity; MUAP, motor unit action potential.

diffuse, is the most common symptom in schwannomatosis patients [8]. Moreover, Gonzalvo et al. [9] described pain as the initial symptom in most patients. MacCollin et al. [6] also presented several cases with schwannomatosis along the course of peripheral nerves.

However, motor weakness by peripheral neuropathies due to schwannomatosis has rarely been reported. Ogose et al. [5] reported a case of incomplete peroneal neuropathy among patients with the extraspinal lesion. Park et al. [1] presented a case of schwannoma involving sciatic nerve, which showed weakness of the gastrocnemius muscle and a posterior tibial neuropathy confirmed by electrodiagnostic studies.

Schwannomatosis is clinically distinguished from neurofibromatosis based on lack of café-au-lait spots and neurofibromas [7]. On MRI finding, fusiform shape and target sign can be seen in either lesions, but several findings can be helpful to differentiate between the two lesions. Eccentrically positioned lesions with different anatomical locations can be schwannoma, whereas centrally located masses can suggest neurofibroma. After gadolinium injection, a small schwannoma has a tendency to be enhanced homogeneously, while large schwannomas can be heterogeneously enhanced [7]. In the present case, biopsy was done from the left leg and schwannoma was confirmed by histology.

Clinicians always need to make a decision to select sufficient image studies based on cost-effectiveness, but sometimes they are insufficient. Therefore, electromyography can be a useful tool to make a correct diagnosis, and localize the disorder. Diagnostic considerations for electromyography could include not only lesions but also proximal and distal nerve involvement along the whole extremities

Although the recurrence of schwannomatosis is rare, there are several reports on recurrence $[6,10]$ as in this case, and the probability of malignant transformation is still unknown.

Surgery is a treatment of choice for solitary schwannoma. However, repeated surgeries are not recommended because of the possibility of iatrogenic nerve injuries and worsening pain. Therefore, management should be focused on prevention of disease progression and strict surveillance $[6,10]$.

In summary, we reported a rare case of segmental schwannomatosis, presenting with motor weakness, with electrodiagnostic confirmation of multiple mononeuropathies. Finally, clinicians should be aware that schwannomatosis could cause variable symptoms including not only pain, but also motor weakness. Strict surveillance and regular follow-up are essential to prevent possible neurological deficits.

\section{CONFLICT OF INTEREST}

No potential conflict of interest relevant to this article was reported.

\section{REFERENCES}

1. Park NK, Lee JH, Kim DS, You JH, Cho IH. Posterior tibial neuropathy by schwannoma in midthigh. J Ko- 
rean EMG Electrodiagn Med 2005;7:139-42.

2. Goldblum JR, Folpe AL, Weiss SW. Enzinger and Weiss's soft tissue tumors. 6th ed. Philadelphia: Elsevier Saunders; 2014.

3. Ferner RE. Neurofibromatosis 1 and neurofibromatosis 2: a twenty first century perspective. Lancet Neurol 2007;6:340-51.

4. Ellis SJ, Gordin S, Edgar MA, Morris CD. Multiple ipsilateral lower extremity masses in a 46 -yearold man. Schwannomatosis. Clin Orthop Relat Res 2007;456:268-74.

5. Ogose A, Hotta T, Morita T, Otsuka H, Hirata Y. Multiple schwannomas in the peripheral nerves. J Bone Joint Surg Br 1998;80:657-61.

6. MacCollin M, Woodfin W, Kronn D, Short MP. Schwannomatosis: a clinical and pathologic study. Neurology 1996;46:1072-9.

7. Pilavaki M, Chourmouzi D, Kiziridou A, Skordalaki A,
Zarampoukas T, Drevelengas A. Imaging of peripheral nerve sheath tumors with pathologic correlation: pictorial review. Eur J Radiol 2004;52:229-39.

8. Merker VL, Esparza S, Smith MJ, Stemmer-Rachamimov A, Plotkin SR. Clinical features of schwannomatosis: a retrospective analysis of 87 patients. Oncologist 2012;17:1317-22.

9. Gonzalvo A, Fowler A, Cook RJ, Little NS, Wheeler $\mathrm{H}, \mathrm{McDonald} \mathrm{KL}$, et al. Schwannomatosis, sporadic schwannomatosis, and familial schwannomatosis: a surgical series with long-term follow-up. J Neurosurg 2011;114:756-62.

10. Molina AR, Chatterton BD, Kalson NS, Fallowfield ME, Khandwala AR. Multiple schwannomas of the upper limb related exclusively to the ulnar nerve in a patient with segmental schwannomatosis. J Plast Reconstr Aesthet Surg 2013;66:e376-9. 